\title{
MIND THE DIGITAL GAP: AMBIENTES DIGITAIS INCLUSIVOS COMO DISPOSITIVOS PEDAGÓGICOS
}

\author{
MONTEIRO, Angélica Maria Reis ${ }^{1}$
}

\begin{abstract}
RESUMO
O presente texto tem por objetivo fundamentar o debate e propiciar reflexão acerca dos ambientes digitais promotores de inclusão digital e a sua relação com o conceito de dispositivo pedagógico (BERNSTEIN, 1990). Do ponto de vista metodológico, foi feita uma revisão de literatura que permitiu identificar as características e os aspectos pedagógicos a ter em consideração na concepção de espaços que respeitem e considerem a diversidade cultural e as características dos sujeitos. Conclui-se que os ambientes educativos podem favorecer a inclusão e diminuir a digital gap, se forem desenhados, desenvolvidos e geridos tendo em consideração as regras dos dispositivos pedagógicos, no que diz respeito a partilha do poder e a recontextualização do discurso pedagógico.
\end{abstract}

PalaVRas-Chave: E-learning - Inclusão digital - Tecnologia - Pedagogia - Dispositivos pedagógiCOS.

\begin{abstract}
This text aims at fostering the debate and encouraging reflection upon digital environments that promote digital inclusion and their relationship with the concept of pedagogical devices (BERNSTEIN, 1990). From a methodological point of view, a literature review was conducted, what allowed to identify the characteristics and pedagogical aspects to be taken into account in the design of spaces that respect and consider cultural diversity as well as the characteristics of each subject. We concluded that educational environments can promote inclusion and reduce the digital gap, if they are designed, developed and managed taking into consideration the rules of pedagogical devices concerning power sharing and the recontextualization of pedagogic discourse.
\end{abstract}

KEYWORDS: E-learning - Digital inclusion - Technology - Pedagogy - Pedagogical devices.

\footnotetext{
${ }^{1}$ Investigadora do Centro de Investigação e Intervenção Educativas CIIE, Faculdade de Psicologia e de Ciências da Educação da Universidade do Porto, Portugal; Investigadora do RECI, docente do Instituto Piaget; Bolsista de Investigação da Fundação para a Ciência e a Tecnologia, FCT. Email: angelica.monteiro@gaia.ipiaget.pt
} 


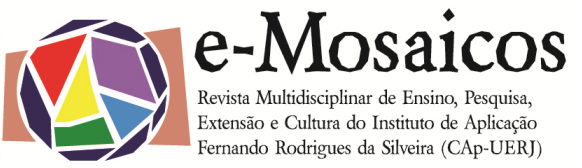

\section{INTRODUÇÃO}

Atualmente vivemos num paradoxo entre a necessidade de, por um lado, sobreviver num mundo cada vez mais competitivo e individualizado e, por outro lado, ter acesso, participar e interagir em redes digitais, como forma de acompanhar os progressos tecnológicos da globalização e como condição sine qua non para a garantia dos direitos de cidadania na "Sociedade de Informação" (CASTELLS, 2002).

Todavia, face à diversidade das pessoas, de situações de vida e de condições econômicas, físicas, psicológicas e culturais, muitas vezes a tecnologia, ao invés de contribuir para a inclusão digital, acaba, ela própria, por ser mais uma fonte de exclusão, acentuando a distância entre os que têm e os que não têm acesso aos meios e ao direito de compreender, usufruir e ter uma voz ativa nos ambientes culturais digitais. Esta lacuna, em língua inglesa, é referida como digital divide ou digital gap. Importa, portanto, identificar essas lacunas e trabalhar em conjunto com os atores, professores, alunos e comunidade, juntamente com as instituições de ensino para as minimizar.

Às instituições de ensino é exigido que adequem a oferta formativa às exigências da sociedade e que preparem os sujeitos para viver em comunidade através do desenvolvimento de competências específicas e transversais, entre as quais as de literacia digital, que inclui uma grande variedade de habilidades cognitivas complexas, tais como motoras, sociológicas e emocionais que os utilizadores precisam de ter para usar ambientes digitais de forma eficaz. Segundo Martin (2005), a literacia digital é o conhecimento, a atitude e a capacidade, da parte dos indivíduos, de utilizar adequadamente as ferramentas digitais e a facilidade de identificar, ter acesso, integrar, avaliar, ana- lisar e sintetizar, criar e comunicar através de recursos digitais.

No sentido de, simultaneamente, dar resposta às exigências da sociedade e de contribuir para o desenvolvimento da literacia digital, algumas instituições têm investido, cada vez mais, na formação continuada dos professores e na integração das tecnologias no currículo. Esta integração pode ser feita, de forma transversal, em todas as disciplinas ou através de disciplinas específicas na área da tecnologia educacional. Há, ainda, instituições que apostam no ensino a distância como oferta alternativa ao ensino presencial (e-learning) ou como complemento às sessões presenciais (b-learning).

Face à diversidade da oferta e das possibilidades pedagógicas em torno dos ambientes digitais de aprendizagem, não é possível garantir que sejam promotores de inclusão digital. Este fato justifica que se procurem respostas para as seguintes questões de partida:

- Quais são os fatores de inclusão e de exclusão em ambientes digitais?

- Qual a relação entre os ambientes digitais inclusivos e o conceito de dispositivo pedagógico?

- De que forma é possível organizar e gerir estes ambientes de modo a reduzir a digital gap?

\section{AMBIENTES DIGITAIS: FATORES DE INCLUSÃO E DE EXCLUSÃO}

A inclusão digital pressupõe, segundo Warschauer (2004), para além do acesso às tecnologias, o estímulo à capacidade de criar e produzir significados e sentidos nos ambientes digitais. Esta deve assegurar que as pessoas excluídas venham a utilizar as Tecnologias de Informação e Comunicação 
(TIC) para expandir as suas competências para uma autoformação que vise uma meIhor qualidade de vida. Esta utilização inclui, segundo Apostopoulou et al. (2004), a capacidade de "manejar, selecionar e produzir informação tendo como finalidade a aprendizagem permanente e o desempenho de um papel ativo na sociedade da informação" (p. 3).

Na mesma linha de raciocínio, Passerino (2011, p. 11) classifica a inclusão digital como "fenômeno social que extrapola o direito de acesso ao mundo digital, focandose na participação significativa das pessoas em práticas culturais específicas em espaços digitais".

Relativamente aos fatores de exclusão digital e, como consequência, potenciadores do aumento da digital gap, Bellini et al. (2012, p. 59) propõem um modelo que identifica três formas básicas de limitações digitais:

- Limitações de acesso (LA), que se referem a dificuldades sociais e materiais de um indivíduo para acessar as tecnologias de informação e comunicação (TICs), re-sultando de restrições econômicas, falta de acesso voluntário, inadequação dos recursos tecnológicos disponíveis, interfaces homem-máquina de baixa ergonomia, ambientes de uso insalubres e outros fatores;

- limitações cognitivo-informacionais (LI), que se referem a dificuldades de um indivíduo relativas às habilidades de fazer uso efetivo das TICs, podendo se manifestar no saber buscar, selecionar, processar e aplicar informações em meios digitais;

- limitações comportamentais (LC), que se referem a dificuldades de um indivíduo para aplicar plenamente suas habilidades digitais, mesmo que as possua em nível elevado, em função de vício em determinadas informações, apatia funcional e outros fatores.

Para que um ambiente digital seja inclusivo deve, portanto, ter em atenção diferentes limitações tecnológicas, tais como as identificadas por Bellini et al. Não basta garantir o acesso aos meios de forma passiva, não diversificada, não adaptada e unidirecional, como é feito com um material didático indiferenciado.

Consoante a utilização pedagógica dos ambientes digitais de aprendizagem, estes podem caracterizar-se como materiais didáticos ou como um dispositivo pedagógico. Recorrendo a Leite (2002, p. 110-111), o material didático tem como "objetivo fundamental aspectos de ordem instrumental que permitam a aquisição de conhecimentos escolares", enquanto o dispositivo pedagógico constitui um "meio de produzir conhecimento num processo de construção de saberes que envolve a participação efectiva dos diversos agentes sociais e desloca o discurso, recolocando-o de acordo com o princípio de reordenação e de recontextualização".

\section{OS AMBIENTES DIGITAIS COMO DISPOSITIVOS PEDAGÓGICOS}

O dispositivo pedagógico, segundo Bernstein (1990), na sua natureza interna, possui três regras hierárquicas: distributiva, de recontextualização e avaliativa. A regra distributiva pressupõe a possibilidade de criar regras específicas de acesso e de controle de poder a diferentes grupos, a regra de recontextualização obriga a constituição de um discurso pedagógico específico e a regra avaliativa constitui a prática pedagógica, justapondo, desta forma, o poder e conhecimento através do dispositivo pedagógico. A figura 1 sistematiza os elementos que compõem os ambientes de aprendiza- 
gem virtuais (LEBARON, PULKKINEN \& SCOLLIN, 2000) e relaciona-os com as "regras" dos dispositivos pedagógicos (BERNSTEIN, 1990).

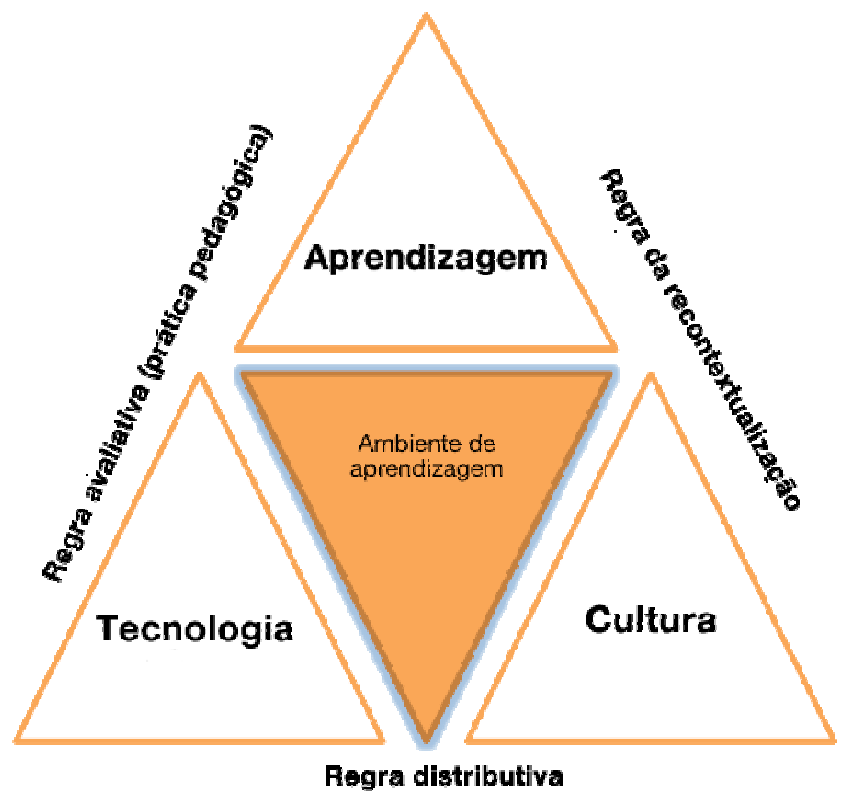

Fig. 1: Os ambientes virtuais enquanto dispositivo pedagógico (retirado de MONTEIRO, LEITE \& LIMA, 2012, p. 34).

Nos três eixos da Figura 1 interagem a tecnologia, a cultura e a aprendizagem. A tecnologia facilita a seleção, a diversificação e a optimização dos meios de distribuição de diferentes tipos de conhecimento a diferentes grupos. Através das regras de recontextualização é produzido um discurso pedagógico específico de acordo com o contexto de transmissão-aquisição da cultura. As regras avaliativas estão presentes na prática pedagógica e esta pode aliar as potencialidades da tecnologia aos processos de aprendizagem pessoais e partilhados (MONTEIRO, LEITE \& LIMA, 2012).

A perspectiva das tecnologias como dispositivos pedagógicos obriga, portanto, a que se reconheçam as diferenças e que se trabalhem com e a partir destas diferenças. Os meios tecnológicos facilitam a diversificação dos meios auditivos e visuais, bem como a sua difusão através de um discurso pedagógico que respeita e valoriza a multiculturalidade, contribuindo, portanto, para reduzir a lacuna digital, no que diz respeito ao acesso e à participação.

\section{ORGANIZAÇÃO E GESTÃO DE AMBIENTES VIRTUAIS DE APRENDIZAGEM TENDO EM VISTA A REDUÇÃO DA DIGITAL GAP}

Os ambientes digitais inclusivos conhecem, reconhecem e valorizam a diversidade cultural dos sujeitos em todas as fases de desenvolvimento, desde a análise do 


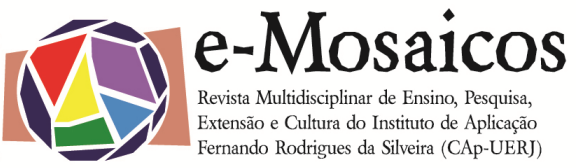

contexto e das características dos participantes, passando pelo desenho e desenvolvimento do ambiente de aprendizagem, até à avaliação formativa do processo e sumativa dos resultados de aprendizagem.

A cultura permite aos alunos, segundo McLoughlin e Oliver (1999), "desenvolver uma âncora cognitiva para novos conhecimentos e lhes permite relacionar e integrar novos conceitos dentro de uma perspectiva coerente que reconhece a diversidade" ( $p$. $10)^{2}$. A partir do mesmo pressuposto, Cruz (2013), num estudo acerca do letramento de jovens com deficiência intelectual, desenvolveu um ambiente virtual de aprendizagem com base na utilização de instrumentos culturais de aprendizagem da cibercultura, designado "AVALER". A autora utilizou letras de canções escolhidas pelos alunos para, a partir de um processo de desconstrução e re-significações, promover aprendizagens acerca da língua escrita e propiciar a interação social e digital:

Foram utilizadas, pelos sujeitos da pesquisa, duas versões do AVALER. A primeira (...) foi desenvolvida a partir da música 'Debaixo dos caracóis dos seus cabelos', de Roberto Carlos e Erasmo Carlos. A segunda apresentou, como caso, a música 'Sorte Grande', de Ivete Sangalo. Foram feitas modificações nas duas versões, a partir da avaliação realizada pelos sujeitos. (idem, p. 124).

Face aos resultados de aprendizagem obtidos, a autora concluiu que a utilização de instrumentos culturais da cibercultura pode significar a remoção de barreiras à participação social e pode possibilitar o a-

\footnotetext{
2 Texto original dos autores: "It enables learners to develop a cognitive anchor for new knowledge and allows them to relate and integrate new concepts within a coherent perspective that recognizes diversity".
}

cesso ao conhecimento de forma interativa e interessante, lúdica, contextualizada (CRUZ \& MONTEIRO, 2013).

Cruz (2011) ressalta, ainda, que os sites e ambientes virtuais de aprendizagem devem dispor de recursos e estratégias de acessibilidade voltados para atender alunos com deficiência e/ou necessidades especiais, tais como: etiquetar imagens (agregar audiodescrição a todas as imagens) e oferecer opções de modificar a fonte e contraste com o fundo, respectivamente para pessoas cegas e com baixa baixa visão; disponibilizar glossários e vídeos com legendas em Língua de sinais, para alunos surdos; oferecer informações em áudio, exibir textos do tipo easyread, ou seja, com linhas curtas, linguagem direta e simples, além de ícones ou símbolos que facilitem a navegação dos alunos com dificuldades cogniticas ou de linguagem.

Um estudo realizado por Reeves (1997) propôs um modelo para a aprendizagem interativa na World Wide Web. Este modelo está organizado a partir de elementos de entrada - hábitos culturais, motivação, atitudes e caraterísticas individuais -; elementos constituintes do processo de ensino-aprendizagem oportunidades de construção de aprendizagens, apropriação de tarefas, noção dos destinatários e do possível impacto e abrangência de um documento publicado online, apoio colaborativo, apoio do professor e apoio à metacognição -; culminando com os resultados de aprendizagem, tais como conhecimentos e competências; modelos mentais robustos e resultados de nível superior (capacidade de resolver problemas, criatividade, curiosidade e o desejo de aprender ao longo da vida).

Este modelo aplica-se a todos os estudantes, independentemente da condição socioeconômica, gênero, etnia ou tipo de 


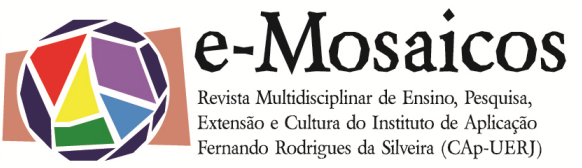

necessidades educativas. McLoughlin e Oliver (1999), ao desenharem um ambiente virtual de aprendizagem para estudantes indígenas, propuseram diretrizes de design para ambientes Web flexíveis e culturalmente sensíveis:

- conceber tarefas que respeitem as diferenças de estilos de aprendizagem e de linguagem;

- criar múltiplos canais de comunicação entre os alunos e o tutor;

- planejar tarefas a partir da diversidade e criar pontes entre a cultura dos alunos e a comunidade;

- capacitar os alunos para produzir recursos e adicionar fontes de informação culturalmente relevantes e valorizar os inputs dos alunos;

- propiciar estruturas de apoio para que os alunos se sintam confiantes e desenvolvam habilidades. $O$ apoio dos próprios pares também deve ser considerado (mentores);

- adotar um postura flexível a respeito dos objetivos, modos de avaliação e resultados de aprendizagem;

- definir papéis diversificados para tutores online e mentores em diferentes fases do curso para garantir o feedback e o apoio;

- propor tarefas motivadoras, nas quais os alunos possam compartilhar ideias e trabalhar em projetos, com base em recursos culturais;

- comunicar claramente as finalidades, os objetivos e os pré-requisitos;

- evitar suposições de escolhas e estereótipos culturais;

- promover a autodireção e a integração das competências.

\section{CONCLUSÕES}

Os ambientes digitais inclusivos favorecem o acesso, a utilização e a participação em ambientes digitais, contribuindo para a produção de novos sentidos individuais ou partilhados.

Relativamente ao acesso, este diz respeito às questões econômicas e sociais, mas também está relacionado com as questões culturais, motivacionais e com as características e necessidades individuais.

A utilização está relacionada com questões pedagógicas, cujas opções devem, obrigatoriamente, privilegiar a interação, a colaboração e estar centradas no aluno e no processo de aprendizagem (LEITE, LIMA \& MONTEIRO, 2009).

A participação está relacionada com a acessibilidade, a partilha do poder e a recontextualização do discurso pedagógico. Esta emerge como processo e como resultado de aprendizagem. $O$ aluno se sente valorizado, confiante e apoiado para fazerse ouvir, para contribuir com o sucesso do grupo, para resolver problemas, para realizar tarefas, para questionar, para dialogar, para produzir conteúdos e partilhá-los, assumindo cada vez mais uma postura crítica necessária para viver em comunidade e para conhecer e reconhecer a sua realidade e transformá-la, em busca de uma melhor qualidade de vida.

Tendo em vista a "bidirecionalidade comunicativa implícita nos ambientes digitais, a facilidade e a necessidade constante de atualização e personalização destes ambientes e a sua consequente constante recriação baseada na interação dos sujeitos" (MONTEIRO, 2011, p. 78), se considera que os ambientes digitais inclusivos se constituem como dispositivos pedagógicos que integram a transmissão e recontextualização cultural na partilha do poder e do conheci- 


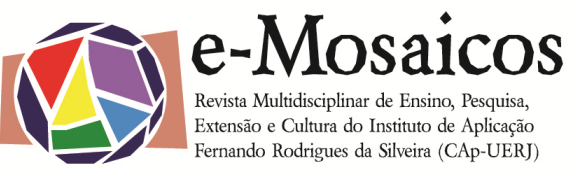

mento e auxiliam a redução da digital gap, tendo em atenção as limitações digitais, sejam elas de acesso, cognitivoinformacionais ou comportamentais.

\section{REFERÊNCIAS BIBLIOGRÁfICAS:}

APOSTOPOULOU, G. et al. E-learning para a Inclusão Social, 2004. Disponível em http://charte.velay.greta.fr/pdf/charter_Elearning_para_inclusao_social.pdf, Acesso em 10/05/2014.

BERNSTEIN, B. Poder, Educación y Consciencia. Sociologia de la transmisión cultural. Barcelona: Edições El Roure, 1990.

BELINNI et al. Limitações digitais: evidências teóricas preliminares. Análise Revista de Administração da PUCRS, v. 23, n. 1, p. 58-70, jan./abr. 2012.

CASTELLS, M. A Sociedade em Rede. Lisboa: Fundação. Calouste Gulbenkian, 2002.

CRUZ, M. L. Ambiente virtual de aprendizagem para letramento de alunos com deficiência intelectual. Tese de doutorado, Universidade do Estado do Rio de Janeiro, 2013.

CRUZ, M. L.\& MONTEIRO, A. Acessibilidade cognitiva para o letramento de jovens com deficiência intelectual. Arquivos Analíticos de Políticas Educativas, 21(74), 2013. Disponível em http://epaa.asu.edu/ojs/article/view/1326 Dossiê Educação de Jovens e Adultos; Editoras convidadas: Sandra Regina Sales \& Jane Paiva, Acesso em 10/10/2014.

CRUZ, M. L. Ambientes virtuais de aprendizagem - recursos para alunos com necessi- dades educacionais especiais. In Monteiro, A. \& Moreira, j. A. Educação online: pedagogia e aprendizagem em plataformas digitais (pp. 117-132). Santo Tirso: De Facto Editores, 2011.

LEITE, C. O Currículo e o Multiculturalismo no Sistema Educativo Português. Lisboa: Fundação Calouste Gulbenkian, 2002.

LEITE, C., LIMA, L.; MONTEIRO, A.. O Trabalho Pedagógico no Ensino Superior: Um olhar a partir do prémio excelência em elearning, na Universidade do Porto. Educação, Sociedade e Culturas, 28, 71-91, 2009.

MARTIN, A. DigEuLit - a European Framework for Digital Literacy: a Progress Report, $2005 . \quad$ Disponível em http://www.jelit.org/65/01/JeLit_Paper_31.p df, Acesso em 10/12/2014.

MCLOUGHLIN, C.; OLIVER, R. Instructional design for cultural difference: $A$ case study of the indigenous online learning in a tertiary context, 1999. Disponível em http://citeseerx.ist.psu.edu/viewdoc/summa ry?doi=10.1.1.33.9346, Acesso em $10 / 10 / 2014$.

MONTEIRO, A. O currículo e a prática pedagógica com recurso ao b-learning no ensino superior. Tese de doutorado. Universidade do Porto, 2011.

MONTEIRO, A; LEITE, C \& LIMA; L. Ensinar e aprender com tecnologias digitais. In MOREIRA, J. A. \& MONTEIRO, A. Ensinar e aprender online com tecnologias digitais. Porto: Porto Editora, 2012.

PASSERINO, L. Indicadores de inclusão digital: Uma análise dos multiletramentos propi- 
ciados em redes sociais online a partir da ótica do posicionamento. QUAESTIO, 13(2), 7-32, 2011.

REEVES, T. C. A model of the effective dimensions of interactive learning on the World Wide Web. Proceedings of Interaktiivinen Teknologia Koulutuksessa (ITK'97), Hameenlinna (Finland), 1997.

WARSCHAUER, M. Technology and Social Inclusion. Rethinking the digital divide. Cambridge, MA: MIT Press, 2004. 